\title{
Nog over het overstromingsgebied van de IJzer in de middeleeuwen, de ,Magna Sclusa" en de abdij Ter Duinen (1184)
}

door

\author{
Roger DEGRYSE
}

In zijn zeer systematische en overzichtelijke studie over de ,historische geografie van het overstromingsgebied van de IJzer in de middeleeuwen" brengt de heer $\mathrm{R}$. Boterberge de kwesties van de loop van het ,aqueductum inter Furnes et Dixmuda" (1183) en de ligging van de "magna sclusa" (1184) te berde. Hij ziet tussen beide kwesties geen enkel verband en aanvaardt niet, dat genoemd kanaal ten oosten van Nieuwpoort zijn uitmonding had en de "magna sclusa" aldaar gelegen was ${ }^{1}$. Om zijn stelling te bewijzen, voert de heer $\mathrm{R}$. Boterberge enkele argumenten aan, die we hier opnieuw willen onderzoeken en trachten te weerleggen.

Vóór 1183 werd op last van graaf Filips van de Elzas een kanaal aangelegd, ten einde Veurne een nieuwe of betere verbinding te water met Diksmuide te verzekeren. Dit weten we dank zij één enkel gegeven. In 1183 inderdaad stelde de vorst het cijfer vast van de geldelijke vergoeding, die enkele "hospites", verbonden aan de abdij van Ename, voor hun onteigende gronden zouden ontvangen ${ }^{2}$. In de desbetreffende oorkonde staat „,aqueductum inter Furnes et Dixmuda", wat de heer R. Boterberge doet besluiten, dat die waterweg onmogelijk over de IJzerhaven, d.i. Nieuwpoort, kan gelopen hebben, alhoewel er uitdrukkelijk aan toegevoegd wordt „inicium habentem ab Ysera". De heer R. Boterberge gaat inderdaad uit van de vaststelling, dat de abdij van Ename nooit bezittingen meer noordwaarts dan Pervijze of de Venepe heeft gehad. Hij verliest evenwel uit het oog, dat in de 12 de en 13 de eeuw het aanleggen van een kanaal zeer dikwijls op kanalisatie van bestaande waterlopen neerkwam. Gezien Veurne aan de Venepe gelegen was, mag men aannemen, dat in de eerste plaats die waterloop gekanaliseerd geworden is. De nieuwe of vernieuwde waterweg kan dan ook bestaan hebben uit een gekanaliseerde verbinding tussen de Venepe, waaraan de parochie Pervijze paalde, en de IJzermonding ten

(1) R. Boterberge. Historische Geografie van bet Overstromingsgebied van de IJzer in de Middeleeuwen, in Handel. Maatsch. Gesch. en Oudh. Gent, dl XVI (1962), blz. 77-142. Zie blz. 116-117.

(2) „Noverint et presentes et posteri quod Philippus, comes Flandrie, jussit fieri aqueductum inter Furnes et Dixmuda, inicium habentem ab Ysera et se longius extendentem per diversas terras...". Ch. Piot. Cartulaire de l'abbaye d'Eename. Bruges, 1881 blz. 63 , nr 68. 
oosten van Nieuwpoort ${ }^{3}$. De volledige tolvrijdom, die Veurne in 1176 van Filips van de Elzas te Nieuwpoort te land en te water ontving, wijst o.i. op het bestaan van deze verbinding ${ }^{4}$, die naderhand de ,,waterghanc" genoemd zou worden ${ }^{5}$. De uitdrukking ,,inicium habentem ab Ysera" betekende ongetwijfeld, dat de eigenlijke waterweg tussen Nieuwpoort en Diksmuide de IJzerstroom volgde ${ }^{6}$.

Het nieuwe kanaal, dat Veurne langs de IJzer met Diksmuide verbond, moet, indien het overeenstemt met de ,waterghanc", zijn monding ten oosten van Nieuwpoort gehad hebben. Daar lag de oostsluis, die wij met de „magna sclusa” vereenzelvigen. Deze identificatie wordt door de heer $\mathrm{R}$. Boterberge verworpen. De „magna sclusa" was een zeer belangrijke sluis, die in 1184 aan de zorgen van de abdij Ter Duinen toevertrouwd werd. De desbetreffende tekst geeft evenwel geen aanduidingen nopens haar juiste ligging. Toch bevat hij een gegeven dat van belang zou kunnen zijn. De abdij zou ook de zorg krijgen over een „alteram slusam” in het

(3) De „Venepe" was eigenlijk de naam voor het in 1138 vernoemde „fossatum quod a Isera usque Furnis extenditur", wat op een reeds bestaande kanalisatie tussen Veurne en de IJzer in de streek van Ramskapelle wijst. Zie R. Boterberge, o.c., blz. 101, kaart 4. - Het nieuwe kanaal was slechts een verdere aanpassing, maar nu langs de Nieuwpoortse haven om. Zie op dezelfde kaart de Koolhofvaart.

(4) L. Gilliodts-Van Severen. Coutumes de la ville et chatellenie de Furnes, dl. III, blz. 23, nr IV. - Ook professor Hans van Werveke zag een verband tussen deze tolvrijdom en het nieuwe kanaal. Bovendien trekt hij de andacht op het woord „jussit” : de graaf „deed”, volgens de oorkonde van 1183, een kanaal tussen Veurne en Diksmuide graven. H. van Werveke. De economische politiek van Filips van de Elzas (1157-68 tot 1191), in Meded. v.d. Kon. Vl. Ac. voor Wet., Let, en Sch. Kunsten v. België. KI. der Let. Jaarg. XIV (1952), nr 3, blz. 3-18. Zie blz. 12. R. Boterberge vraagt zich af of dit kanaal werkelijk gegraven geworden is. Hoe dan de onteigeningen, waarvan in 1183 sprake is, te verklaren?

(5) Nieuwpoort lag ten westen van de, waterghanc". Dit blijkt uit de kadastrale beschrijving van deze stad van 1314 met de opsomming van de "parken" met huizen onderworpen aan de heffing van "'s gravenlandschuld". De opsomming begint met de vermelding, dat al wat ,boesten waterganghe licghet van der moenche huus es een paerc". Park 2 begint met "Jehan Camerlinck westward over vander sluus oup de gracht zuutward...". Met "moenche huus" werd het huis van de Duinenabdij en met "sluus" de oostsluis bedoeld. Het kadaster werd uitgegeven door R. de Beaucourt de Noortvelde in zijn werk, waarvan alleen deel II verscheen : Nieuport. Documents bistoriques. Ostende, 1904, blz. 111-166. De tekst van de uitgave laat veel te wensen over.

(6) "IJzer" was in de middeleeuwen niet alleen de naam voor de stroom of "fluvium Ysere" (anno 850), maar ook voor de stroommonding in meer beperkte zin. In de Engelse documenten worden de lieden van Nieuwpoort eenvoudig aangeduid als zijnde herkomstig van de IJzer. H.J. Smit. Bronnen tot de gescbiedenis van de bandel met Engeland, Schotland en Ierland, deel I (1150-1485), passim. - „Burgenses et homines nostri portus de Novoportu, qui vulgariter dicitur Yssera..." Rymer. Foedera, conventiones etc. D1. I, blz. 142. Stuk van 14 augustus 1274 nopens de arrestatie van Nieuwpoortse vissers te Northam nabij Berwick upon Tweed. Zelfs indien in 1183 met Ysera de stroom bedoeld werd, dan is daar nog de vaststelling, dat in 1138 het oudere kanaal van Veurne of Venepe nabij Ramskapelle in de IJzer liep. Daar lag trouwens nog omstreeks 1140 de "Yseram portum", wat zou kunnen laten veronderstellen, dat de IJzermonding op dat ogenblik nog tot nabij Ramskapelle reikte. F. Van de Putte. Cronica et cartularium monasterii de Dunis, blz. 443. Oorkonde van kort na 1138. - De kwestie, waar deze "Ysera portus" gelegen was, wordt door R. Boterberge niet aangeraakt. 
noordelijk gedeelte van haar domein, de Grote Hemme, indien dergelijk waterwerk aldaar opgericht moest worden. Daaruit besluit de heer R. Boterberge, dat de "magna sclusa" zich in het zuidelijk gedeelte van de Grote Hemme, d.i. in de Venepe, moet gesitueerd worden en met de daar gelegen Venepesluis te vereenzelvigen is ${ }^{7}$.

Een argument, dat tegen de stelling van de heer $\mathrm{R}$. Boterberge pleit, is het grondbezit van de abdij Ter Duinen ten oosten van Nieuwpoort nabij de oostsluis. De oorsprong van dit bezit moet o.i. in de zorg van de monniken over de "magna sclusa" gezocht worden. Ongetwijfeld heeft Filips van de Elzas, toen hij in 1184 aan Ter Duinen opdracht gaf zich met het onderhoud van deze sluis in te laten, tevens toestemming verleend aldaar een stuk bodem in bezit te nemen om er een sluishuis op te richten. Deze grond maakte evenwel deel uit van het aanslibbingsgebied Zande(s)hoofd ${ }^{8}$, waarop de O.-L.-Vrouwabdij van Burburg sinds 1107 rechten had ${ }^{9}$.

(7) „... eo tenore ut ipsi fratres magnam sclusam sub sua custodia debeant conservare, et quicquid propter maris inondationem que fossatum rumpat, fodiendo refeci... Vero si casa aliquo prefata slusa aut poenibus destructa au vetustate consumpta aut aliquid magni de ejus machina fuerit confractum, nichilomnino ad fratrum spectabit industriam vel impensam, sed communi totius populi restaurabitur expensa... Porro si in septentrionali parti Hem, alteram slusam, consideratione utilitatis, construi contigit, in solido ac tuso ponetur loco et eam cum gottis suis, lege superioris, fratrum cura tueri tenebitur". F. Van de Putte, o.c., blz. 166, nr 277. Oorkonde van 22 maart 1184 (n.s.), waardoor Filips van de Elzas de Duinenabdij ontslaat van belastingen op haar landerijen in Veurne-Ambacht gelegen. Zie ook R. Boterberge, o.c., blz. 113 en 116. - In deze tekst is er, in verband met de "magna sclusa" en het „fossatum", wel degelijk sprake van overstroming door de zee, wat op de nabijheid van de kust en een zeesluis wijst. Bovendien blijkt duidelijk uit de tekst, dat de zorg over de "magna sclusa" zoveel als een openbare dienst was, waaraan de polderbevolking van gans de kasselrij, die niet aan de Duinenabdij onderworpen was, moest medewerken. De tegenstelling met de eventueel op te richten ,alteram slusam" is opvallend, vermits die gesitueerd wordt en wel in het noordelijk deel van de Grote Hemme (zie Boterberge, blz. 101, kaartje). In de tekst wordt evenwel niet gezegd, dat de ,magna sclusa" voor de afwatering van het Hemmegoed moest dienen en nog minder, dat ze er in het zuidelijk deel lag. Toch concludeerde de hr Boterberge daaruit, ,dat, zoals zij (de monniken) nu (in 1184) de ,magna sclusa” ten zuiden van de Hemme onderhouden, zij eventueel ook voor de zorg van de ,altera slusa" ten noorden van de Hemme zullen moeten instaan". Zie R. Boterberge o.c., blz. 117. Eigenlijk neemt de schrijver min of meer de interpretatie van G. Van de Woude over, daar waar deze beweert: „In 1183 verkrijgen de monniken de toelating een sluis te bouwen in het noordelijk gedeelte van de Hemme, dus in de nabijheid van Nieuwpoort. Ten zuiden van de hoeve was een veel belangrijker sluis Venepesluis genoemd...". Zie G. Van de Woude. Ter Duinen, kustmacbt onder de graven. Antwerpen, 1944, blz. 37. - Zie ook blz. 36: G. Van de Woude aanvaardt aldaar toch de identificatie van de ,magna sclusa" met de Nieuwpoortse oostsluis.

(8) De filologische verklaring van de plaatsnaam Sandeshovetha (1168) of Zandehoefth (1272) schijnt op moeilijkheden te stuiten wegens de aanwezigheid van de genitief $-s$, die nochtans niet steeds voorkomt. Sommige filologen verwerpen de verklaring alsof Zande(s)hoofd de betekenis van zandhoofd, zandig duinland, zou hebben en menen, dat de meest aanneembare hypothese zou zijn: hoofd of vooruitspringend gedeelte van een duinland, Sand genoemd. Later zou de term Sandeshoved, Zande(s)hoofd, de naam van het gehele zand geworden zijn. J. De Langhe. Toponomyca uit de kuststreek, in Biekorf, jaar 1960, blz. 146-148, naar Gysseling, in Mededelingen Naamkunde, dl 35 (1959), blz. 67-68. - Dat Zande(s)hoofd een misvorming van, ,zandig hoofd" zou zijn, willen wij zo maar niet onmiddellijk verwerpen, aangezien op oude kaarten van de IJzermonding de term "sandich landt" 
Met deze rechten blijkt de graaf alsdan geen rekening gehouden te hebben, evenmin als toen hij twintig jaar voordien, in 1163, op het duin Zande(s)hoofd de stad Nieuwpoort stichtte ${ }^{10}$. De heer $R$. Boterberge haalt een oorkonde aan, waaruit zou moeten blijken, dat eerst omstreeks 1190 Ter Duinen in het bezit van een stuk grond ten oosten van Nieuwpoort zou gekomen zijn. Volgens een verklaring door abt Amilius van Baudelo in 1233 afgelegd, bezat de abdij inderdaad toen sinds meer dan 43 jaar, krachtens een gift van Filips van de Elzas, een ,domum et terram apud Nieuweport" "11. Deze diende echter als plaats, waar de conversen en vissers hun haringnetten konden drogen, en dus niet als sluishuis. Met „Nieuweport" werd bovendien niet de IJzerhaven bedoeld, maar Grevelinge, dat omstreeks 1190, evenals Nieuwpoort, nog een ,novus portus" of nieuwe stad was ${ }^{12}$. Dit wordt bevestigd door twee bekrachtigingsoorkonden van vóór 1200, dus van kort na de schenking ${ }^{13}$.

Dat het grondbezit van Ter Duinen tot 1184 opklimt, is uit latere bronnen af te leiden. Wel is waar werd de abdij eerst in 1241 door gravin Johanna en graaf Thomas in het bezit gesteld van het perceel gronds, 192 roeden groot, dat tussen de twee sluizen, waaruit waarschijnlijk de ,magna sclusa" bestond, gelegen was ${ }^{14}$. Uit een inventaris van het bezit van de

voorkomt. Zie Alg. rijksarch. te Brussel. Kaarten en plannen. Mns 293. Kaart van het einde van de $17 \mathrm{e}$ eeuw (1661?). Rechteroever.

(9) R. Boterberge, o.c., blz. 124-126 - ,... novam terram nomine Sandeshove, que per iactum maris iam crevit et quicquid in posterum accrescet super fluvium Ysare sitam". F. Vercauteren. Actes des comtes de Flandre, blz. 103, nr 37.

(10) Eerst in 1272 legde de O.L.Vrouwabdij van Burburg zich bij deze onteigening neer: „Et parmi ce li abbeesse et li couvens devant dites cuitent et ont cuitet le terre ke on appele Zandehoefth, u ore en partie siet li vile de Nueport...". L. Gilliodts-Van Severen. Coutumes de la ville et du port de Nieuport, in Coutumes des Pays et Comté de Flandre, quartier de Furnes, t. V., Bruxelles, 1901, blz. 162, nr XIV. Oorkonde van februari 1272 (n.s.). - Voor de stichting van Nieuwpoort, zie: R. Degryse, 's Graven domein te Nieuwpoort (in de middeleeuwen), in Hand. Soc. Em. Brugge, dl LXXXV (1948), blz. 72-74. - R. Boterberge, blz. 126.

(11) „quod ecclesia de Dunis ex dono pie memorie Philippi, comitis Flandrie, omni tempore quo ego fui in ordine, per quadraginta tres annos et amplius, habuit domum et terram aput Nieweport, ubi recia sua sicare solent et extendere conversi eiusdem ecclesie piscatores...". F. Van de Putte et C. Carton. Chronique de l'abbaye de Ter Doest, blz. 47, nr XIX. Stuk van mei 1233.

(12) H. Van Werveke, o.c., blz. 5.

(13) „quinque mensuras partim dunarum, partim werplandii mei apud Grevenigga ad recia desiccanda" - „quinque mensuras partim dunarum, partim werplandii, ex donatione comitis Philippi, apud Grevenigem ad piscatorum retia desicanda". V.d. Putte, Cron. et cart. de Dunis, blz. 174 en 266. Bekrachtigingsoorkonden, respectievelijk van graaf Boudewijn IX, anno 1197 of daaromtrent, en paus Innocentius III van 21 mei 1199. - R. Boterberge steunt hier nogmaals op Van de Woude, o.c., blz. 51 en 131.

(14) „Eodem anno (1241), mense junio, Thomas et Joanna... dederunt in perpetuam eleemosinam suam mensuram jacentem inter duas aquaductus slusarum versus aquilonem juxta Neoportum habentem in latitudine $a b$ oriente in occidentem duodecim virgas et in longitudine ab austro in aquilonem sexdecim virgas". Ad. de Budt. Cronica abbatum monasterii de Dunis, uitgave C.L. Carton, Brugis, 1839, blz. 116. - G. Van de Woude, O.c., blz. 130. - Reeds in 1233 is er sprake van een huis met grond van de Duinenabdij nabij Nieuwpoort : „extra Novum Portum infra dicum", C.C.D., blz. 363. Stuk van december 1233. 
abdij, die in 1246 op bevel van gravin Margaretha gemaakt werd, vernemen we evenwel, dat de totale oppervlakte gronds, die Ter Duinen ten oosten van Nieuwpoort langs de IJzer in bezit genomen had, 24 gemeten bedroeg ${ }^{15}$. In 1269 besliste de gravin, tot regeling van een geschil tussen ter Duinen en Veurne-Ambacht, dat de abdij de zorg over de ,verse" deur, een van de beide deuren van de oostsluis bij Nieuwpoort, behield, maar dat de door de monniken aangestelde sluismeester onder het toezicht van de watergraven van Veurne-Ambacht zou staan ${ }^{16}$. Deze uitspraak bewijst dat Ter Duinen er steeds de zorg over de deur of de deuren moet gehad hebben en dat de sluis zelf slechts met de vroegere „magna sclusa” kan vereenzelvigd worden.

De geleidelijk inpalming door de Duinenabdij van een ,hem sive utdiic monachorum" ten oosten van Nieuwpoort en de oostsluis beviel op de duur allerminst aan de O.-L.-Vrouwabdij van Burburg. Deze verkreeg in 1272 van gravin Margaretha, in ruil voor haar rechten op het gedeelte van Zande(s)hoofd, waarop de stad Nieuwpoort zich uitgebreid had, de officiele erkenning van het bezit van haar ,hemmekin" of "utdiic comitis", gelegen ten oosten van het door de Duinenabdij gewonnen land ${ }^{17}$. Met dit klooster zelf sloot ze in 1275 een akkoord, dat zoveel als een "modus vivendi" was. Daardoor bleef Ter Duinen in het bezit van haar ,utdiic", waarvan de oppervlakte ondertussen van 24 tot 26 gemeten aangegroeid was ${ }^{18}$. In de desbetreffende oorkonde staat duidelijk, dat het deel van Ter Duinen gelegen was "prope sclusas et domibus in eo fundo constructis". Er kan dus geen sprake zijn, zoals de heer R. Boterberge beweert, van een nieuwe

(15) ,Item, ad orientiem ville, que dicitur Nieuport, mansuram in qua domus de Dunis sita est cum appendiciis suis et viginti quatuor mensuris terre". F. Van de Putte. C.C.D., blz. 200. - R. Boterberge, blz. 127.

(16) De verse deur of ,fres wis del ecluse ki est a Noefport" was de deur, die op het kanaal uitkwam. De andere deur, langs de kant van de IJzerhaven, was de zoute deur. Dit wijst er op dat de sluis bestond uit een sas. In de oorkonde, dagtekenend van april 1269, is er overigens sprake van de doorvaart van schepen: „des neis ki i passeront". F. Van de Putte. C.C.D., blz. 357. - R. Boterberge, blz. 118.

(17) ,ke comme nos boenes amies li abbeesse et li couvens de Bourbourg demandaissent dedent le banliewe de Nueport une terre ke on apele le hemmekin ke li mers a jetee, et ki onques ne fu dikie par le raison dune chartre que li abeesse et li couvens devant dit ont de nos ancestres sour chou ke jet de meir ki en cele partie poroit accroistre deveroit estre leur...". Het hemmekin strekte zich uit tot de ,dic $\mathrm{ke}$ on apele le dic le conte u cil des Dunes orent jadis une maison dedenz le dic devers le terre" en had een oppervlakte van 29 en $1 / 8$ gemeten. L. Gilliodts-Van Severen. Coutumes de Nieuport, o.c., blz. 162, nr XIV. Stuk van februari 1272 (n.s.). - R. Boterberge, blz. 126.

(18) ,... questionem movissemus super quodam fundo sito super fluvium Ysare ex parte orientali ville Novi Portus prope sclusas et domibus in eodem fundo constructis cum pertinentiis et appenditiis suis ac quibusdam novis terris circiter viginti sex mensuris cum accrementis suis presentibus et futuris super predictum fluvium Ysare et prope dictum fundum sitis, hem sive utdiic monachorum vulgariter nominatis, contiguis et confinibus terre nove ecclesie nostre que hem sive utdiic comitis communiter dicebatur, ecclesie nostre nuper libertate a comite Flandrie... quos nos nomine ecclesie nostre dicebamus jure dominii vel quasi ex donatione comitum Flandrie pertinere...". V.d. Putte. C.C.D., blz. 411. Stuk van 12 mei 1275. - De O.-L.-Vrouwabdij van Burburg ontving als vergoeding voor het geleden verlies (,,pro compositione") 30 pond parisis. Adr. de Budt. Cron. de Dunis, o.c., blz. 122. 
aanwinst van de monniken, waardoor hun grondbezit ten oosten van Nieuwpoort tot 50 gemeten gestegen zou zijn ${ }^{19}$. De ,modus vivendi" van 1275 kan slechts geinterpreteerd worden als een toepassing van de verworven rechten van de Duinenabdij op de bodem nabij de oostsluis. Deze rechten zelf kunnen alleen verklaard worden, indien men de oostsluis met de „magna sclusa”, waarover het klooster in 1184 de zorg kreeg, vereenzelvigt. Overigens waren na 1275 de duinenabdij en de O.-L.-Vrouwabdij van Burburg gezamenlijk werkzaam bij het aanleggen van nieuwe dijken ten oosten van Nieuwpoort. Dit gaf zelfs in 1293 aanleiding tot een conflict met deze stad, die gans de ,havene" stroomafwaarts van Nieuwendamme wenste te controleren ${ }^{20}$. In 1294 verbood graaf Gwijde aldaar alle verdere indijking. Tevens gaf hij de gemeente Nieuwpoort toelating stroomafwaarts van Nieuwendamme spuien op te richten ${ }^{21}$. Toch zouden naderhand beide genoemde kloosters gezamenlijk nog gronden ten oosten van Nieuwpoort indijken ${ }^{22}$.

De oostsluis was niet de enige sluis, die nabij Nieuwpoort de afwatering van Veurne-Ambacht regelde. Dergelijke sluis, de westsluis, lag aan de westkant van de stad nabij de haven ${ }^{23}$. De afwateringskanalen omheen Nieuwpoort vormden een boog, naderhand de ,ryole” genoemd. Gans dit

(19) „In 1275 kocht Ter Duinen nog 26 gemeten nieuw land te Nieuwpoort, nabij haar Hem, van de O.-L.-Vrouwabdij van Broekburg voor 30 pond parisis, waardoor Ter Duinen alsdan in het bezit kwam van 50 gemeten". R. Boterberge, blz. 127. - Niets is minder waar, aangezien in de desbetreffende tekst geen kwestie is van aankoop, maar van compromis, gesteund op de scheidsrechterlijke uitspraak van gravin Margaretha.

(20) ,Et si doit tous li avenes demorer entirement a le ville de Noefport, tout ausi comme il lont mannie et tenu iuskes au jour dui". Gemeenschappelijke keure van Nieuwpoort en Lombardsijde van april 1269 (oude of nieuwe stijl), art. 7. L. Gilliodts-Van Severen. Coutumes de Furnes, dl IV, Coutumes de Lombardside, blz. 14-16, nr II. - Betreffende het conflict tussen Nieuwpoort en de beide abdijen, zie de bijlage hieronder: tekst van een. Nieuwpoortse schepenbrief van 7 mei 1293, waarin sprake is van de "diic kil (de twee abdijen) vellent faire en la terre kon appele Hem deles la ville de Nuport". Deze oorkonde wordt door R. Boterberge niet besproken.

(21) ,et que nus ne puist dikier dedens le havene devant dit". Oktrooi en uitspraak van graaf Gwijde van 4 januari 1294 (n.s.), als antwoord op de Nieuwpoortse vraag tot bemiddeling van 7 mei 1293. L. Gilliodts-Van Severen. Coutumes de Nieuport, o.c., blz. 174, nr XXV. - Boterberge, blz. 119.

(22) R. Boterberge, blz. 127, betreffende indijkingen omstreeks 1350. - „Anno eodem (1349), factum est concordatum inter abbatem Dunensem et abbatissam de Burborgh pro dicandis terris juxta Neoportum, communibus expensis". Ad. de Budt, o.c., blz. 129.

(23) Het ,fossatum" ten westen van Nieuwpoort wordt reeds vermeld in 1240 : ,debent limitari parrochie supradicte versus aquilonem usque in mare per quoddam fossatum, quod dividit pasturas occidentalium dunarum a pasturis dunarum ballivie Noviportus". Scheidsrechterlijke regeling van de begrenzing van de parochies Oostduinkerke en Nieuwpoort. L. Gilliodts-Van Severen. Coutumes de Nieuport, blz. 156, nr VIII. - De westsluis wordt eerst in 1307 vermeld : . . lescluse mouvante qui est entre le havene et ledit polre (van Jan van Namen) ainssy comme le Kocxstrate sessent vers la mer jusques au dyc...". Akte van aankoop door de stad Nieuwpoort van de polder van Jan van Namen, gelegen ten westen van de agglomeratie. Ibidem, blz. 178, nr XXVII. De Kokstraat loopt van zuid naar noord, dus evenwijdig met het ,fossatum" aldaar. 
stelsel van kanalen en sluizen moet tot stand gekomen zijn als gevolg van de werken, die op last van Filips van de Elzas, na de stichting van Nieuwpoort, uitgevoerd geworden waren. Tot die werken behoorden — zoals we hebben pogen te bewijzen - ongetwijfeld ook de kanalisatie van de verbinding te water tussen Veurne en de IJzermonding en de oprichting van de "magna sclusa" aan het uiteinde van dit kanaal ten oosten van Nieuwpoort. Dit wordt trouwens bevestigd door de traditie, daar waar die het in 1350 heeft over de ,waterganc daer de houde sluus in leghet" 24 en in 1374 over ,,den waterghanc die loopt bin der stede van der Nieuwerpoort, dien van Veurn Ambocht toebehorende" ${ }^{25}$. Een andere verklaring voor de oorsprong van de oostsluis en het grondbezit van de abdij Ter Duinen ten oosten van Nieuwpoort is moeilijk te geven.

(24) „so es gheacordert, dat die brugghe, die leght over den waterganc daer de houde sluus in leghet, zullen die van Veurnambocht ende die van der Niewerpord houden half ende half van alle costen...". F. Van de Putte, C.C.D., blz. 734, nr 1846. Akkoord gesloten in de Duinenabdij betreffende het onderhoud van "drien brugghen ligghende over de "niewe ryole".

(25) ,van dat die van der Niewerpoort tooghden ende zeiden, dat zij van zo ouden tiden, dat niemen de contrarie ghedinken mochte, ghecostumert hadden te ladene ende ontladene met scepen alle manieren van goede in den waterganc van dien van Veurn-Ambocht bin der stede ende vrihede van der Niewerpoort...".

"... dat die van der Niewerpoort van oydts tiden gheladen ende ontladen hebben in den ouden waterghanc ende in den niewen van dien van Veurn Ambocht...".

„.... dat die van der Niewerpoort den vorseiden waterganc sullen houden voortan up haers selfs cost 30 roeden lang upwaert te lande waert in streckende van der sluus..." N. de Pauw, Bouc van der Audiencie. Acten en sentencien van den Raad van Vlaanderen (1369-78). Gent, 1901-'07, blz. 810, nr 1714. Sentencie van $10 \mathrm{dec}$. 1375. Zie ook blz. 624, nr 1322. Sentencie van juli-augustus 1374.

„van scepen die uut Veurn Ambocht varen deur de havene ter Niewerport, die men heet zeelopers...". Ibidem, blz. 809, nr 1713. Sentencie van 10 dec. 1375. 


\section{BIJLAGE}

Nieuwpoort, 7 mei 1293.

Brief van de schepenen en het gemeen van de stad Nieuwpoort, waardoor dezen zich onderwerpen aan de uitspraak van graaf Gwijde in het geschil, dat ze hebben met de abdij Ter Duinen en de O.-L.-Vrouwabdij van Burburg, nopens de oprichting door deze laatsten van een dijk ter bescherming van de hemmelanden van Nieuwland, de latere Groot Noord Nieuwlandpolder, te Sint-Joris aan de IJzer.

Origineel: Gent. Rijksarchief. Oorkonden van de graven van Vlaanderen. Chronologisch supplement nr 171 (voor het ogenblik tentoongesteld in de Permanente Tentoonstelling te Anderlecht, nr 130).

Zegel: verdwenen.

Stempel: Archives de l'Etat à Gand.

Op de rug: Lettre de le ville de Neufport ki se mettent sour le dit le conte Guy dou debat ki est entre eus dune part et labbe des Dunes et labbesse de Bourbourg dautre part dun dijck kil voelent faire a hem deles Nuef port.

In later geschrift (19e eeuw): Copié pour l'administration communale de Nieuport.

Stempel: Archives du Conseil de Flandre.

A tous cheaus qui ces presentes lettres verrunt et orunt. Nous eschevins et toute li communites de le ville de Nuport salus en notre seigneur. Nous vous faisons a savoir que comme content et debas est entre nous dune part et honoraules gens religieus et sages mon singneur labbe et li couvent de Dunes et ma dame labbesse et le covent de Brughburgh dautre part si comme dun diic kil vellent faire en la terre kon appele hem deles la vile de Nuport gisant envers la paroche de Saint George kon appele Nieweland que nous otroions et obligons nous tous que tout chou que nostre treskier singneur Guis cuens de Flandres et marchis de Namur dira et ordonera dehaut et debaes des coses devant dites que nous le tenrons ferm et estauble perpetuelment. En tesmongnages de la queles coses desus dites nous avons ces presentes lettres pendant saelees de no sael qui furent faites en lan del incarnation notre singneur mil CC quatre vins et tresse le jour del assention. 